\title{
Human adaptation to climate change: An introduction to the special issue
}

Anne C. Pisor ${ }^{1,2 *}$ \& James Holland Jones ${ }^{3}$

\section{[ACCEPTED MANUSCRIPT: AMERICAN JOURNAL OF HUMAN BIOLOGY]}

\author{
${ }^{1}$ Department of Anthropology, Washington State University, Pullman, WA 99164-4910 \\ ${ }^{2}$ Department of Human Behavior, Ecology, \& Culture, Max Planck Institute for Evolutionary \\ Anthropology \\ ${ }^{3}$ Department of Earth System Science, Stanford University \\ *Corresponding author: anne.pisor@wsu.edu
}

Objectives. Despite our focus on adaptation and human responses to climate, evolutionary and biological anthropologists (EBAs) are largely absent from conversations about contemporary "climate-change adaptation," a term popular in other disciplines, the development world, and related policy decisions. EBAs are missing a big opportunity to contribute to impactful, timesensitive applied work: we have extensive theoretical and empirical knowledge pertinent to conversations about climate-change adaptation and to helping support communities as they cope. This special issue takes a tour of EBA contributions to our understanding of climate-change adaptation, from data on past and contemporary human communities to theoretically informed predictions about how individuals and communities will respond to climate change now and in the future. First, however, we must establish what we mean by "climate change" and "adaptation," along with other terms commonly used by EBAs; review what EBAs know about adaptation and about human responses to climate change; and identify just a few topics EBAs study that are pertinent to ongoing conversations about climate-change adaptation. In this article, we do just that. Conclusion. From our work on energy use to our work on demography, subsistence, social networks, and the salience of climate change to local communities, EBAs have an abundance of data and theoretical insights to help inform responses to contemporary climate change. We need to better reach the climate community and general public with our contributions.

KEYWORDS. Climate change, adaptation, climate-change adaptation, biological anthropology, evolutionary anthropology, science communication 
The Canadian speculative-fiction author, Margaret Atwood, suggested that climate change is not simply climate change; it's everything change ${ }^{1}$. Climate change is the central challenge to humanity of the $21^{\text {st }}$ century. Concerned with how humans will cope with climate change, climate researchers, development partners, and policymakers (henceforth, the climate community) increasingly refer to "climate-change adaptation," a phrase that loosely means reducing exposure to the negative consequences of climate change. Evolutionary and biological anthropologists (EBAs) have a long history of studying human-environment interactions and adaptation; in line with the original meaning in biology, we generally understand adaptation to mean increasing the fit between an organism and its environment. However, despite our investment in the study of adaptation and of human-environment interactions more broadly, EBAs are largely absent from conversations and policy decisions pertinent to climate-change adaptation. What do EBAs know that would be relevant to the climate community as they make decisions about how to support vulnerable populations coping with climate change? What data do we already have that are applicable? How can we better collect climate-change-relevant data going forward? Highlighting the pertinence of an anthropological understanding of adaptation, existing anthropological data about human responses to climate, and ways forward, this special issue begins to answer these questions.

In this introductory article, we review concepts that will be used throughout this special issue, including what we mean by "climate change" and "adaptation"; briefly introduce the role of climate change in shaping human evolution; and identify some of the major topics studied by EBAs that are relevant to the climate community, providing examples from contributions in this issue. We close by providing a short overview of strategies that EBAs can use to better engage with the climate community, strategies that we cover in more detail in a large collaborative piece (Jones et al. a, this issue).

\section{What is climate change?}

In common usage, the phrase "climate change" has become conflated with anthropogenic climate change - the role of human activity in contemporary climate change. Broadly writ, however, climate change refers to changes in the distributional properties (e.g., mean, variance) of climate characteristics like temperature and precipitation that persist across decades (see Glossary; Christopher B. Field et al., 2014). Because precipitation is related to temperature, scientists often focus on changes in global temperature as an indicator of climate change. (If the focus is on increases in average global temperature, this is sometimes called "global warming.") Carbon dioxide $\left(\mathrm{CO}_{2}\right)$ levels have an outsized impact on global temperatures by preventing heat from escaping from Earth's atmosphere, an effect called "the greenhouse effect"; because of this, atmospheric $\mathrm{CO}_{2}$ is often used as a proxy for average global temperatures. As evidenced by $\mathrm{CO}_{2}$ and other indicators, climate change has characterized all of Earth's history (Fletcher et al., 2008). It is a product of myriad processes, including features of the Earth's orbit, tectonic activity, and asteroid impacts (Cronin, 2009). However, there is scientific consensus for the large role of human activity in climate change since at least 1970 (Rosenzweig et al., 2008). Suggestive

${ }^{1}$ https://medium.com/matter/it-s-not-climate-change-it-s-everything-change-8fd9aa671804 
evidence points to anthropogenic effects on global climate by 1600 or earlier (Lewis \& Maslin, 2015), though substantial uncertainty remains in the precise timing (Zalasiewicz et al., 2010).

\subsection{What is the relevance of climate change to humans?}

Climate change has exerted selection pressures on hominins (subfamily Hominini) throughout human evolution (Behrensmeyer, 2006; Levin, 2015; Stanley, 1992). The last common ancestor of Homo sapiens and the genus Pan (including chimpanzees, Pan troglodytes, and bonobos, Pan paniscus) is believed to have speciated as a result of climate change, namely the reduction in continuous forest in Africa due to cooling and drying at the end of the Miocene epoch. Selection pressures on the savanna likely favored new adaptations for foraging and locomotion (Moore, 1996). Likewise, the increasing efficiency of bipedal locomotion in australopithecines (Paranthropus and Australopithecus spp.) is often attributed to a climate-related reduction in gallery forests (see Lieberman, 2014 for a review). Climate change may be responsible for the change in foraging ecology with the transition to the genus Homo (e.g., increased emphasis on hunted game; Kaplan et al., 2000). Further, climate-related changes in paleoecology around the Sinai Peninsula may have permitted the repeated movements of Homo species out and into Africa (Ash \& Gallup, 2007). In short, human evolution has been greatly shaped by climate change; in fact, if we consider the phylogenetic history of any species alive today, we will see the products of selection pressures related to climate change.

Climate change continued to be an important selective force for our species, Homo sapiens, over the last approximately 300,000 years. During the Pleistocene epoch, rapid global temperature variation may have favored complex culture in humans (Richerson \& Boyd, 2000). Though the current epoch, the Holocene, has had fewer large-scale fluctuations in global temperatures than the Pleistocene, regional or global changes in average temperature and precipitation during the Holocene have had outsized effects on cultural evolution, including on the emergence of new forms of subsistence (including horticulture, pastoralism, and agriculture) and the persistence of cities and states (Fagan, 2005; Richerson et al., 2001). Today, global climate change threatens billions of people (Xu et al., 2020), especially communities living in poverty (Olsson et al., 2014). For many Indigenous communities, climate change is one component of a "total environment of change" (Moerlein \& Carothers, 2012), including social and economic change, that are altering Indigenous lifeways (Kramer \& Hackman, this issue; Ready \& Collings, this issue).

Climate change has always been relevant to humans and our ancestors. As this special issue will demonstrate, the climate community can learn a great deal about adaptation in the face of climate change by taking a long view of human history and prehistory.

\section{What is adaptation?}

When the climate community refers to "climate-change adaptation," they are usually referring to the changes humans make in response to or in anticipation of the negative effects of climate change (IPCC, 2012 Pisor \& Jones, this issue). To translate, climate-change adaptation is implicitly cultural adaptation (see Mesoudi, 2016 for a review of the concept), although it is not always 
clear who is adapting (e.g., individuals, communities, states) or how (Jones et al. b, this issue). For example, some in the climate community suggest that climate-change adaptation can be bottom-up, emerging from the actions of communities, or top-down, imposed by governments or international organizations (Smit \& Wandel, 2006). If we step away from the "climate change" part, the definition of adaptation in the climate community is tantamount to the changes humans make (Thornton \& Manasfi, 2011). Under this definition, it is unclear what is not adaptation. For example, while some authors are careful to distinguish adaptation from coping (Pelling, 2010), the International Panel on Climate Change offers overlapping definitions (Christopher B. Field et al., 2014). Without a clearer conceptualization of what constitutes climate-change adaptation, it is difficult to generate a priori predictions about how humans may respond to contemporary climate change (Pisor \& Jones, this issue) and to support communities as they generate their own responses (Jones et al. $b$, this issue).

Though they may not be aware of their agreement, many anthropological traditions implicitly agree on a definition of adaptation: something that manages the risks posed by the environment (Jones et al. b, this issue). To EBAs, adaptations are phenotypic traits - not just genetically or epigenetically encoded adaptations, but also cultural adaptations (for a review, see Jablonka \& Lamb, 2014) - that promote fitness by solving the persistent problems faced by a lineage of individuals (Lewontin, 1978). Genetically encoded adaptations are often plastic, with norms of reaction that yield a range of phenotypes across variable environments; some in the EBA community may call these "physiological adaptations" (Stinson et al., 2012) or "facultative adaptations" (Buss, 2011). Because of this plasticity, adaptations can often respond to contemporary environmental variability, changing the phenotype accordingly, if this variability was also experienced by an individual's ancestors (Kuzawa \& Bragg, 2012). Though archaeologists have at times been wary of the word "adaptation" (Kohler \& Rockman, n.d.), many have discussed the strategies humans use to manage risks (Braun \& Plog, 1982; Halstead \& O'Shea, 1982, 1989; Minc \& Smith, 1989; Minnis, 1985; O’Shea, 1981; Spielmann, 1986). Indeed, a menu of risk-management strategies introduced by archaeologists (Halstead \& O'Shea, 1982, 1989) later found its way into manuscripts about climate-change adaptation written by environmental anthropologists and a political scientist (Agrawal, 2010; Thornton \& Manasfi, 2011). Further, several traditions in cultural anthropology, including cultural ecology, ecological anthropology, and environmental anthropology, largely agree that adaptation is inherently about managing environmental risks (Crate, 2011; Moran, 2018; Sutton \& Anderson, 2014; Vayda \& McCay, 1975).

While anthropological consensus usefully narrows the definition of climate-change adaptation, two important discrepancies remain. First, is there any precedent for anticipatory adaptation in humans? While humans and other generalist species exhibit substantial phenotypic plasticity in response to environmental conditions, there is general consensus among those taking an evolutionary perspective to adaptation, including EBAs, that natural selection is not anticipatory and will not favor adaptations to potential future conditions never experienced by an individual or its ancestors (Gould \& Vrba, 1982). Cultural ecologists, ecological anthropologists, and archaeologists largely agree. Should we then expect humans to be any good at developing and implementing anticipatory cultural adaptations to future climate change, as the climate community suggests humans can? Second, who or what adapts to climate change? When we talk about adaptation, are we talking about genetically encoded adaptations that successfully 
managed the risks posed by past climate change (e.g., Richerson et al., 2001)? Are we talking about individual responses to climate change via phenotypic plasticity, be it behavioral (including traits adopted through cultural transmission) or biological? Are we talking about communitylevel or population-level adaptations to climate change that arise through local innovation and/or spread via cultural practices from other communities or populations? To productively narrow what is meant by "climate-change adaptation" such that researchers can make and test explicit predictions about the risk-management strategies humans will use in the face of contemporary climate change, these discrepancies in meaning must be resolved. (See Jones et al. b, this issue, for further discussion.)

\subsection{The biological definition of adaptation}

When EBAs talk about adaptation, both in this special issue and in general, the concept is used as both a noun (adaptation) and as a verb (adapting; see Glossary). As a noun, an adaptation refers to an aspect of the phenotype that manages risks posed by the environment (Jones et al. b, this issue). It is an outcome of the verb form: process of adapting. Per Ernst Mayr's (1997) conception of natural selection as "non-random elimination," adaptations ultimately work to minimize the risk of zeros in survival and reproduction - that is, the risk of dying or failing to reproduce (Price \& Jones, 2020). At a proximate level, however, adaptations work on other currencies studied by EBAs and other social scientists such as subsistence (Bliege Bird \& Bird, this issue; Hazel et al., this issue; Kramer \& Hackman, this issue; Otárola-Castillo et al., this issue; Ready \& Collins, this issue), social capital (Douglass \& Rasolondrainy, this issue; Hazel, this issue; Pisor \& Jones, this issue; Scaggs et al., this issue), household income, and happiness or satisfaction (Price \& Jones, 2020). Adaptations can be transmitted from individual to individual by genetic, epigenetic, or cultural pathways. Accordingly, an adaptation is something that exists at the individual rather than at the population level. (When EBAs talk about "populations," we usually are referring to a group of people who intermarry, consistent with the use of the term in evolutionary demography; see Glossary.) However, when we think of the verb form of the concept, it denotes the process of adapting (Lewontin, 1978). Adapting occurs at the population level as adaptive variants increase in relative frequency because they help manage environmental risk and thus are favored by selection. This selection - essentially feedback between the phenotype and the environment - can be natural or cultural selection.

Most EBAs hold that behavioral adaptations are not anticipatory. Anthropologists generally agree that humans have the phenotypic traits we have because these traits helped individuals, whether in the distant or recent past, manage the risks posed by their environment (Douglass \& Rasolondrainy, this issue; Jones et al. b, this issue). Though environmental conditions in the future may reflect past conditions, given human evolutionary history has been molded by climate change (Section 1.1), this is no guarantee, especially as humans have greatly altered the quantity of our energy use and given the rapidity of contemporary climate change (Pontzer, this issue). That said, while anthropologists generally agree that adaptations are designed to respond to conditions faced by our genetic or cultural ancestors, anthropologists do not think humans are helpless when it comes to responding to novel challenges. First, cultural adaptation can happen quickly, even across the span of days or weeks, as a behavioral adaptation increases in frequency; 
this process has only been accelerated by mass communication (Acerbi, 2019; Cavalli-Sforza \& Feldman, 1981). When presented with a novel challenge, an individual may copy behavioral adaptations from others that are consistent with their existing cultural knowledge (Sperber, 1985) or that appear to avoid costs they may face (Fessler et al., 2014). Second, humans have the genetic adaptations to actively design cultural adaptations: adaptation and agency are not opposites (Smith, 2013; Smith \& Wishnie, 2000). In short, while adaptations are not anticipatory, humans can be quite responsive to novel challenges, generating new candidate adaptations that can spread rapidly through the population. Promoting diversity in and among communities within that population will in turn increase the diversity of candidate adaptations, providing individuals with a menu of options to selectively adopt and transmit (Jones et al. $b$, this issue).

If each adaptation has a function which serves to manage risk, we must distinguish what an adaptation is for from what it does. Adaptations spread in populations because they helped individuals manage environmental risks in the past; that means that today they may function differently if environments have changed, generating novel benefits (Gould \& Vrba, 1982) or costs (Brady et al., 2019). Failing to distinguish current outcomes from original function is a "functionalist trap," a fallacy to which the climate community, and even some EBAs, are susceptible (Ensminger, 1994). EBAs have a toolkit devoted to figuring out what adaptations were for when they evolved, from observing an adaptation today and modeling how it would respond to a past environment, to modeling how an adaptation would respond to a past environment and observing today whether an adaptation matches the model, to comparing adaptations from different species (genetic adaptations) or cultures (cultural adaptations) to infer what features of local environments they are responding to (Sterelny \& Griffiths, 1999). We may find it easier to illustrate the difference between what an adaptation is for and what it does, and to thus demonstrate the utility of our toolkit, by using the concept of "maladaptation." When a formerly adaptive trait generates more novel costs than novel benefits, both the climate community and EBAs focus on what the trait does rather than what it is for; both communities call these traits maladaptations (Brady et al., 2019; United Nations Environment Program, 2019). By emphasizing how studying the design properties of traits can help us distinguish adaptation from maladaptation, and thus "for" from "does," we can enhance our ability to generate policy impacts. (See also Jones et al. b, this issue.)

\section{Anthropologists' work is relevant for understanding climate-change adaptation}

As highlighted by the articles in this special issue, there are many domains in which EBAs have theoretical approaches, expertise, and data relevant to larger conversations about human responses to climate change. By showcasing our archaeological, laboratory, and field data, EBAs can encourage the climate community not to reinvent the wheel, but to use existing data (e.g., Douglass \& Cooper, 2020; Kohler \& Rockman, n.d.), combined with a principled definition of adaptation, to anticipate how communities will respond to climate change and to support them as they do.

One of EBA's most important contributions is our emphasis on continuity: adapting to climate change is nothing new for humans and may, in fact, be a defining feature of our genus (Potts, 2012). What is novel is the extent to which our current predicament is self-made, as human 
energy use over the last approximately one million years precipitated anthropogenic climate change today (Pontzer, this issue). For example, EBAs have studied the effects of both past and present climate change on human demography, including mobility - that is, a temporary or permanent change of residence (Templon et al., this issue). Whether we are discussing climate change 13,000 years ago (e.g., Otárola-Castillo et al., this issue) or today, once changes in the mean or variance of temperature or precipitation reach a particular threshold -- for example, in terms of their positive autocorrelation or the severity of extreme weather events (Templon et al., this issue; Pisor \& Jones, this issue) -- individuals respond by moving to a location where they believe resources will be more available, either temporarily (Bliege Bird \& Bird, this issue; Douglass \& Rasolondrainy, this issue) or permanently (Templon et al., this issue). Mobility as a behavioral adaptation, including strategies for where to go (Templon et al., this issue) and whom to visit (Pisor \& Jones, this issue), is often culturally transmitted across generations (Douglass \& Rasolondrainy, this issue).

Many human adaptations, not just mobility, function to maintain resource access. EBAs have both the theoretical framework and the data to make predictions about how individuals will maintain this access in the face of anthropogenic climate change. For example, EBAs often study how individuals protect against the downsides of risk by diversifying their resource portfolios (Scaggs et al., this issue). Pastoralists who raise animals that are more resilient to drought have greater resource security when precipitation falls (Hazel et al., this issue). As predicted by foraging theory, during times of resource scarcity, foragers often become generalists, focusing less on specializing in particular resources (Otárola-Castillo et al., this issue). Importantly, for individuals to effectively reduce the impact of climate change on their resource access, they must be permitted to use the behavioral adaptations they have for maintaining access. Foragers around the globe, both past and present, have managed the downsides of climate variability with fire -- for example, to drive prey or to modify the landscape such that prey are more accessible or easily captured (Bliege Bird \& Bird, this issue; Pontzer, this issue). If Indigenous peoples are not permitted to use their traditional practices to manage risk, they are less well-positioned to cope with contemporary climate change (Bliege Bird \& Bird, this issue).

Both in the past and in the present, individuals' social networks have been key to ensuring mobility and resource access given climate variability (Cashdan, 1985; Kaplan et al., 1990; Scaggs et al., n.d.; Wiessner, 1982), and EBAs use our understanding of human sociality to make predictions about the kinds of network connections individuals will make. While connections with kin often help individuals to manage day-to-day variation in production, when faced with longer intervals of wet or dry weather, or cold or hot temperatures, individuals often turn to partners with whom they have reciprocal sharing relationships (Bird et al., 2019; Waddell, 1975; Wiessner, 1982) - especially if these individuals produce different resources (Scaggs et al., this issue). Indeed, EBAs predict (and often find) that people prefer social partners who are unlikely to experience resource shortfalls at the same time as them; when the experience of shortfalls is not correlated across partners, this permits the pooling of risk (Pisor \& Jones, this issue; Winterhalder, 1980). In order to have a network of social partners who are unlikely to experience correlated shortfalls, individuals may build connections both within and between communities (Douglass \& Rasolondrainy, this issue; Pisor \& Jones, this issue). Further, social network connections are not only sources of food or monetary resources, but also of behavioral 
adaptations. Network connections transmit innovations for managing the risks posed by climate change (Douglass \& Rasolondrainy, this issue; Jones et al. b, this issue). Importantly, however, even if individuals can acquire new adaptations through their social network connections, they may not be able to utilize these adaptations. Conflicts of interest between members of a household, larger family, or community can prevent individuals from deploying their behavioral adaptations when the downsides of climate change strike (Hazel et al., this issue; Templon et al., this issue).

EBAs' work on mobility, resource access, and social networks has import beyond the level of communities, scaling up to regional and even trans-national levels -- scales often of interest to members of the climate community. For example, our work on sustainable resource management and conservation, especially our work on cooperation, collective action, and resource harvesting, has reached broad audiences because local patterns have global consequences (Alvard et al., 2003; Borgerhoff Mulder \& Coppolillo, 2005; Costanza et al., 1998; Waring et al., 2015). With respect to climate change, our focus on mobility as an adaptation to environmental risks permits us to make a priori predictions about when people will leave (Pisor \& Jones, this issue; Templon et al., this issue) and how far they will go (Bliege Bird \& Bird, this issue; Douglass \& Rasolondrainy, this issue; Otárola-Castillo et al., this issue; Pisor \& Jones, this issue; Templon et al., this issue), which usually involves moving within a country (Templon et al., this issue) but can involve crossing international borders (Wiessner, 1982). Our work on differences in human energy use across modes of production (e.g., foraging, intensive agriculture) can be used to better understand both when anthropogenic climate change began and individual contributions to carbon emissions today (Pontzer, this issue). Our theoretical work on the recurrent structures of human social networks and how they foster and transmit adaptations has implications for the emergence of climate-change adaptation on a global scale (Jones et al. b, this issue). In sum, though one of the strengths of anthropology is our in-depth understanding of dynamics within communities, this understanding scales up to larger patterns of human behavior; EBAs are actively pursuing these extrapolations and their broader implications.

Though the work done by EBAs has much to offer larger conversations about climate-change adaptation, our work also offers a caution: when it comes to life on the ground in the $21^{\text {st }}$ century, climate change is not always as salient to stakeholders as it is to the climate community. Climate change refers to increases or decreases in the mean and/or variance of features of climate, like temperature or precipitation, across decades. For horticulturalists or foragers, variation across seasons or across years is often more salient than these longer-term trends (Kramer \& Hackman, this issue). Further, though climate change often directly affects food resources, it can also affect the means of production, for example, by limiting mobility (Pisor \& Jones, this issue; Ready \& Collings, this issue). Research on climate-change adaptation that ignores other pressing issues communities face on a daily basis - the "total environment of change" (Moerlein \& Carothers, 2012), which includes poverty and legacies of colonialism - risks being both scientifically flawed and (at best) irrelevant for local communities (Kramer \& Hackman, this issue; Ready \& Collings, this issue; Scaggs et al., this issue). 
Taken together, EBAs often draw on evolutionary theory and our knowledge of human evolutionary history to make a priori predictions about how behavioral adaptations function, whether we evaluate these predictions by collaborating with living peoples or studying the archaeological record. Our theoretical and empirical knowledge base permits us to forecast how people will respond to contemporary climate change, including through the strategic use of mobility (e.g., at what thresholds of resource stress will individuals migrate?), the management of subsistence risk (e.g., what resources are individuals likely to use to protect against the downsides of climate change?), and the formation of social capital (e.g., where are the connections in an individual's social network likely to live?). Further, we are well-positioned to even make predictions about how people will think about climate change, given the time scales of climate variability most salient on the ground. In short, EBAs have both a theoretical approach and data that would greatly contribute to ongoing conversations about climate-change adaptation. Participating in these conversations, however, requires that we engage in outreach and make these resources available to the climate community and the general public (Jones et al. a, this issue). It also means that we need to engage with and listen to the communities with whom we collaborate (Broesch et al., 2020; Kramer \& Hackman, this issue; Ready \& Collings, this issue).

\subsection{Demonstrating the relevance of anthropology}

Given that EBAs have a theoretical approach and an array of data relevant to both the climate community and the general public, how do we reach these stakeholders? Based on the experiences of many of the contributors to this special issue, in Jones et al. (a, this issue) we make explicit recommendations for how to build bridges to the climate community and the public. We include illustrative examples that readers may find useful for increasing their engagement and outreach while simultaneously collaborating with and listening to local, Indigenous, and descendant communities. To provide a brief teaser here, our explicit recommendations include broader public engagement, including writing public pieces such as press releases, opinion pieces, and trade publications that explain research in terms of a story; collaborating with researchers in other disciplines, which cultivates our abilities to communicate results across boundaries of terminology and methodology; and improving diversity, professional mentorship, and networking opportunities for early-career scholars.

\section{Conclusion}

Climate change is the central challenge of the 21st century, yet somehow, despite all we know about human responses to climate and about adaptation, evolutionary and biological anthropologists (EBAs) are largely absent from conversations about climate-change adaptation and from decision-making about how to best support communities vulnerable to climate change. In this article, we established what "climate change" and "adaptation" mean, among other terms commonly used by EBAs that appear throughout this special issue (see Glossary). We then reviewed the extent to which climate change has affected human evolution and why a biological definition of adaptation clarifies that (1) adaptation is almost exclusively reactive, rather than 
anticipatory of future conditions - though reactivity does not imply that individuals are powerless to respond, and to respond quickly, and (2) an adaptation is for a particular function, and EBAs have the toolkit for investigating the functions of adaptations; what an adaptation does as a byproduct should be a separate consideration. We also provided a short tour of just a few of the research areas in which EBAs have much to contribute to the conversation about climate-change adaptation, including our work on energy use, mobility, subsistence, social networks and cultural change, and the relevance (or not) of climate change in the day-to-day life of communities.

Why should EBAs invest the energy to make our work accessible to stakeholders such as climate researchers, development partners, policymakers, and the general public? First, given the wideranging and profound impacts of contemporary climate change, there is perhaps no better target for our applied work. Gibson and Lawson (2014) provide an eloquent argument for why EBAs should consider applied work as a complement to their other interests. Second, even though the climate community is already making policy decisions that affect the communities with whom we collaborate -- communities that are often among the most vulnerable to the downsides of climate change -- few of us are bringing what we know about these communities to the table to help inform decision-making on the part of local, regional, or national governments, policy think tanks, or intergovernmental institutions charged with responding to climate change. Assuming the communities with whom we collaborate agree that we can share their data and stories, or the data and stories of their ancestors, we need only build the bridge so that our empirical work and ideas can reach climate change stakeholders (see Jones et al. $a$, this issue, for tips on how to do so). EBAs will then be better positioned to help support communities vulnerable to climate change as they cope.

Acknowledgments. Thanks to Rebecca Bliege Bird, Kristina Douglass, Elspeth Ready, Mary Towner, and an anonymous reviewer for comments on this manuscript. A special shout-out to the babies born during the production of this issue to the Gerkey, Otárola-Castillo, and Pisor families.

\section{Glossary to the special issue}

Actor: An individual, group, community, culture, or nation-state with some degree of autonomy for decision-making regarding its welfare. In the climate science literature, researchers often do not specify whether adaptations (see Adaptation) exist at the level of the individual or the community. Accordingly, we use "actor" to specify that the entity in question can be anything from an individual to a nation-state.

Adaptation, as a noun: A phenotypic trait (see Phenotype) that imbues its bearer a higher probability of reproducing itself than the bearers of other phenotypic traits in a particular environment at a particular time. In other words, if a given trait is more effective than are other traits at managing the downside and/or the upside of a risk posed by a particular environment at a particular time, the actors carrying the adaptation are more likely to reproduce themselves, and thus reproduce the trait, than actors that do not carry it (Section 2; see Actor, Selection). We then call that trait an adaptation. 
Adapt, as a verb: The process by which adaptations increase in frequency in a population through selection -- in other words, the process by which actors become better suited to their environments (Section 2; see Evolution, Population).

Anthropogenic climate change: Climate change attributable to human behavior; a number of other processes have also generated climate change across Earth's history (Section 1; see Climate change).

Climate change: Regional or global changes in the distributional features (usually the mean or variance) of climate variables (e.g., temperature, precipitation, extreme weather events) through time (Section 1).

Demography: The size, dynamics, and composition of populations across time; the processes that generate these changes, the foci of study for demographers, are usually "vital events": birth, death, mobility (see Mobility and migration), and marriage.

Evolution: Change in the frequencies of different characteristics through time. The characteristics can be morphological, physiological, or behavioral (see Phenotype) and transmitted culturally, epigenetically, or genetically.

Horticulture: A subsistence (see Subsistence) pattern in which households grow domesticated plants without irrigation or plows, often accompanied by the husbandry of small domesticated animals (e.g., pigs, chickens). Also called "slash and burn farming" or "shifting cultivation" because horticulturalists cycle through the same plots across years, cutting down and burning foliage to replenish nitrogen levels in the soil.

Mobility and migration: Although the terms are sometimes used interchangeably, demographers and EBAs usually use migration to refer to a permanent change in residence and mobility to refer to a temporary change in residence (e.g., "migrant labor" is actually closer to mobility than to migration). In the present article, we use "mobility" and clarify whether this is short-term mobility (a temporary change in residence) or long-term mobility (a permanent change in residence).

Niche construction: An evolutionary process characterized by feedback between an actor and its environment such that the actor modifies its environment, either actively (e.g., by constructing a structure like a hive or a building) or passively (e.g., distributing seeds by eating fruit and passing seeds through the digestive system), and these changes to the environment in turn exert selection pressures on the actor.

Pastoralism: A subsistence pattern in which households raise domesticated herd animals as their primary source of food and/or cash income. The consumption of milk, blood, and occasionally meat is supplemented by plant products, which households obtain by trade or by maintaining small gardens.

Phenotype: A trait (see Trait) carried by an actor on which selection (see Selection) can act directly; this direct action distinguishes a phenotype from a genotype.

Population: A group of individuals that intermarry (or, more broadly, that reproduce together). 
Risk: A decision is said to carry risk if its outcome is variable. Risks are often described with the metaphor of a lottery: outcomes are paid out according to some probabilistic process and involve both upsides and downsides.

Selection: Selection includes cultural and natural selection. It refers to the ability of some inherited characteristics to reproduce themselves better than others in a particular environment at a particular time (see Adaptation, Adapt, and Evolution). Note that our use of "selection" here differs from cohort selection, which occurs through attrition or differential frailty. Unlike natural or cultural selection, cohort selection does not include reproduction and subsequent amplification of characteristics better fit to the environment in a particular place and time.

Social capital: The sum total of resources in their social network (see Social network) that an actor can mobilize for instrumental action.

Social network: The aggregate of the social relationships of an actor.

Subsistence: How an actor obtains its food.

Trait: A quantifiable measurement of an organism.

\section{REFERENCES}

Acerbi, A. (2019). Cultural Evolution in the Digital Age. Oxford University Press.

Agrawal, A. (2010). Local institutions and adaptation to climate change. In R. Mearns \& A. Norton (Eds.), Social Dimensions of Climate Change: Equity and Vulnerability in a Warming World (pp. 173-198). The World Bank. https://doi.org/10.4337/9781785365119.00009

Alvard, M. S., Robinson, J. G., Redford, K. H., \& Kaplan, H. (2003). The sustainability of subsistence hunting in the Neotropics. Conservation Biology, 11(4), 977-982. https://doi.org/10.1046/j.1523-1739.1997.96047.x

Ash, J., \& Gallup, G. G. (2007). Paleoclimatic variation and brain expansion during human evolution. Human Nature, 18(2), 109-124.

Behrensmeyer, A. K. (2006). Climate change and human evolution. Science, 311(5760), 476478. https://doi.org/10.1126/science.1116051

Bird, D. W., Bird, R. B., Codding, B. F., \& Zeanah, D. W. (2019). Variability in the organization and size of hunter-gatherer groups: Foragers do not live in small-scale societies. Journal of Human Evolution, 131, 96-108. https://doi.org/10.1016/j.jhevol.2019.03.005

Borgerhoff Mulder, M., \& Coppolillo, P. (2005). Conservation. Princeton University Press.

Brady, S. P., Bolnick, D. I., Angert, A. L., Gonzalez, A., Barrett, R. D. H., Crispo, E., Derry, A. M., Eckert, C. G., Fraser, D. J., Fussmann, G. F., Guichard, F., Lamy, T., McAdam, A. G., Newman, A. E. M., Paccard, A., Rolshausen, G., Simons, A. M., \& Hendry, A. P. (2019). Causes of maladaptation. Evolutionary Applications, 12(7), 1229-1242. https://doi.org/10.1111/eva.12844 
Braun, D. P., \& Plog, S. (1982). Evolution of "tribal" social networks: Theory and prehistoric North American evidence. American Antiquity, 47(3), 504-525. https://doi.org/10.1525/aa.1961.63.5.02a00100

Broesch, T., Crittenden, A. N., Beheim, B., Blackwell, A. D., Bunce, J., Colleran, H., \& Hagel, K. (2020). Navigating cross-cultural research: methodological and ethical considerations. In PsyArXiv. https://doi.org/doi:10.31234/osf.io/thqsw

Buss, D. (2011). Evolutionary Psychology: The New Science of the Mind. Pearson.

Cashdan, E. (1985). Coping with risk: Reciprocity among the Basarwa of Northern Botswana. Man, 20(3), 454-474.

Cavalli-Sforza, L. L., \& Feldman, M. W. (1981). Cultural transmission and evolution: A quantitative approach (Vol. 16). Princeton University Press.

Costanza, R., Andrade, F., Antunes, P., den Belt, M. van, Boersma, D., Boesch, D. F., Catarino, F., Hanna, S., Limburg, K., Low, B., Molitor, M., Pereira, J. G., Rayner, S., Santos, R., Wilson, J., \& Young, M. (1998). Principles for Sustainable Governance of the Oceans. Science, 281(5374), 198-199. https://doi.org/10.1126/science.281.5374.198

Crate, S. A. (2011). Climate and culture: Anthropology in the era of contemporary climate change. Annual Review of Anthropology2, 40, 175-194.

Cronin, T. M. (2009). Paleoclimates: Understanding Climate Change Past and Present. Columbia University Press.

Douglass, K., \& Cooper, J. (2020). Archaeology, environmental justice, and climate change on islands of the Caribbean and southwestern Indian Ocean. Proceedings of the National Academy of Sciences of the United States of America, 117(15), 8254-8262. https://doi.org/10.1073/pnas.1914211117

Ensminger, J. (1994). The political economy of religion: An economic anthropologist's perspective. Journal of Institutional and Theoretical Economics (JITE) / Zeitschrift Für Die Gesamte Staatswissenschaft, 150(4), 745-754.

Fagan, B. (2005). The Long Summer: How Climate Changed Civilization. Grants Books.

Fessler, D. M. T., Pisor, A. C., \& Navarrete, C. D. (2014). Negatively-biased credulity and the cultural evolution of beliefs. PLOS ONE, 9(4).

https://doi.org/10.1371/journal.pone.0095167

Field, Christopher B., Barros, V. R., Mach, K. J., \& Mastrandrea, M. D. (2014). Technical summary. In Climate Change 2014: Impacts,Adaptation, and Vulnerability. Part A: Global and Sectoral Aspects. Contribution of Working Group II to the Fifth Assessment Report of the Intergovernmental Panel on Climate Change (pp. 35-94). Cambridge University Press. https://www.ipcc.ch/site/assets/uploads/2018/02/WGIIAR5-TS_FINAL.pdf

Fletcher, B. J., Brentnall, S. J., Anderson, C. W., Berner, R. A., \& Beerling, D. J. (2008). Atmospheric carbon dioxide linked with Mesozoic and early Cenozoic climate change. Nature Geoscience, 1(1), 43-48. https://doi.org/10.1038/ngeo.2007.29 
Gibson, M. A., \& Lawson, D. W. (Eds.). (2014). Applied Evolutionary Anthropology: Darwinian Approaches to Contemporary World Issues. Springer Publishing. https://doi.org/978-14939-0280-4

Gould, S. J., \& Vrba, E. S. (1982). Exaptation - a missing term in the science of form. Paleobiology, 8(1), 4-15.

Halstead, P., \& O'Shea, J. (1982). A friend in need is a friend indeed: Social storage and the origins of social ranking. In C. Renfrew \& S. Shennan (Eds.), Ranking, Resource and Exchange (pp. 92-99). Cambridge University Press.

Halstead, P., \& O'Shea, J. (1989). Introduction: Cultural responses to risk and uncertainty. In P. Halstead \& J. O'Shea (Eds.), Bad Year Economics: Cultural Responses to Risk and Uncertainty (pp. 1-7). Cambridge University Press.

IPCC. (2012). Glossary of terms. In C.B. Field, V. Barros, T. F. Stocker, D. Qin, D. J. Dokken, K. L. Ebi, M. D. Mastrandrea, K. J. Mach, G.-K. Plattner, S. K. Allen, M. Tignor, \& P. M. Midgley (Eds.), Managing the Risks of Extreme Events and Disasters to Advance Climate Change Adaptation (pp. 555-564). Cambridge University Press.

Jablonka, E., \& Lamb, M. J. (2014). Evolution in four dimensions, revised edition: Genetic, epigenetic, behavioral, and symbolic variation in the history of life. MIT press.

Kaplan, H., Hill, K., \& Hurtado, A. M. (1990). Risk, Foraging, and Food Sharing Among the Ache. In E. Cashadan (Ed.), Risk and uncertainty in tribal and peasant societies (pp. 107-143). Westview Press.

Kaplan, H., Hill, K., Lancaster, J., \& Hurtado, a. M. (2000). A theory of human life history evolution: Diet, intelligence, and longevity. Evolutionary Anthropology: Issues, News, and Reviews, 9(4), 156-185. https://doi.org/10.1002/1520-6505(2000)9:4<156::AIDEVAN5>3.3.CO;2-Z

Kohler, T. A., \& Rockman, M. (n.d.). The IPCC: A primer for archaeologists.

Kuzawa, C. W., \& Bragg, J. M. (2012). Plasticity in human life history strategy: Implications for contemporary human variation and the evolution of genus Homo. Current Anthropology, 53(SUPPL. 6). https://doi.org/10.1086/667410

Levin, N. E. (2015). Environment and Climate of Early Human Evolution. Annual Review of Earth and Planetary Sciences, 43(1), 405-429. https://doi.org/10.1146/annurev-earth-060614105310

Lewis, S. L., \& Maslin, M. A. (2015). Defining the Anthropocene. Nature, 519(7542), 171-180. https://doi.org/10.1038/nature14258

Lewontin, R. C. (1978). Adaptation. Scientific American, 239(9), 212-230. https://doi.org/10.1038/scientificamerican0978-212

Lieberman, D. (2014). The Story of the Human Body: Evolution, Health, and Disease. Vintage.

Mayr, E. (1997). The objects of selection. Proceeding of the National Academies of Sciences1, 94(6), 2091-2094. https://doi.org/10.1073/pnas.94.6.2091 
Mesoudi, A. (2016). Cultural evolution: A review of theory, findings and controversies. Evolutionary Biology, 43, 481-497. https://doi.org/10.1007/s11692-015-9320-0

Minc, L. D., \& Smith, K. P. (1989). The spirit of survival: cultural responses to resource variability in North Alaska. In P. Halsread \& J. O'Shea (Eds.), Bad Year Economics: Cultural Responses to Risk and Uncertainty (pp. 8-39). Cambridge University Press. https://doi.org/10.1017/CBO9780511521218.003

Minnis, P. E. (1985). Social Adaptation to Food Stress: A Prehistoric Southwestern Example. University of Chicago Press.

Moerlein, K. J., \& Carothers, C. (2012). Total Environment of Change: Impacts of Climate Change and Social Transitions on Subsistence Fisheries in Northwest Alaska. Ecology and Society, 17(1). https://doi.org/10.5751/es-04543-170110

Moore, J. (1996). Savanna chimpanzees, referential models and the last common ancestor. In W. C. McGrew, L. F. Marchant, \& T. Nishida (Eds.), Great Ape Societies (p. 275). Cambridge University Press.

Moran, E. F. (2018). Human Adaptability: An Introduction to Ecological Anthropology. Routledge.

O'Shea, J. (1981). Coping with scarcity: Exchange and social storage. In A. Sheridan \& G. Bailey (Eds.), Economic Archaeology: Towards an Integration of Ecological and Social Approaches (B.A.R. Int, pp. 167-181). B.A.R.

Olsson, L., Opondo, M., Tschakert, P., Agrawal, A., Eriksen, S. H., Ma, S., Perch, L. N., \& Zakieldeen, S. A. (2014). Livelihoods and poverty. In Christopher B. Field, V. R. Barros, D. J. Dokken, K. J. Mach, M. D. Mastrandrea, T. E. Bilir, M. Chatterjee, K. L. Ebi, Y. O. Estrada, R. C. Genova, B. Girma, E. S. Kissel, A. N. Levy, S. MacCracken, P. R. Mastrandrea, \& L. L. White (Eds.), Climate Change 2014: Impacts, Adaptation, and Vulnerability. Part A: Global and Sectoral Aspects. Contribution of Working Group II to the Fifth Assessment Report of the Intergovernmental Panel on Climate Change (pp. 793-832). Cambridge University Press.

Pelling, M. (2010). Adaptation to Climate Change: From Resilience to Transformation. Taylor \& Francis.

Potts, R. (2012). Evolution and Environmental Change in Early Human Prehistory. Annual Review of Anthropology, 41(1), 151-167. https://doi.org/10.1146/annurev-anthro-092611-145754

Price, M. H., \& Jones, J. H. (2020). Fitness-maximizers employ pessimistic probability weighting for decisions under risk. Evolutionary Human Sciences, 2(e28). https://doi.org/10.1017/ehs.2020.28

Richerson, P. J., \& Boyd, R. (2000). Climate, culture, and the evolution of cognition. In C. Heyes \& L. Huber (Eds.), Evolution of Cognition (pp. 329-346). MIT Press.

Richerson, P. J., Boyd, R., \& Bettinger, R. L. (2001). Was agriculture impossible during the Pleistocene but mandatory during the Holocene? A climate change hypothesis. American Antiquity, 66(3), 387-411. 
Rosenzweig, C., Karoly, D., Vicarelli, M., Neofotis, P., Wu, Q., Casassa, G., Menzel, A., Root, T. L., Estrella, N., Seguin, B., Tryjanowski, P., Liu, C., Rawlins, S., \& Imeson, A. (2008). Attributing physical and biological impacts to anthropogenic climate change. Nature, 453(7193), 353357. https://doi.org/10.1038/nature06937

Scaggs, S., Gerkey, D., \& McLaughlin, K. (n.d.). Linking subsistence harvest diversity and productivity to adaptive capacity in an Alaskan food sharing network.

Smit, B., \& Wandel, J. (2006). Adaptation, adaptive capacity and vulnerability. Global Environmental Change, 16(3), 282-292. https://doi.org/10.1016/j.gloenvcha.2006.03.008

Smith, E. A. (2013). Agency and Adaptation: New Directions in Evolutionary Anthropology. Annual Review of Anthropology, 42(1), 103-120. https://doi.org/10.1146/annurev-anthro092412-155447

Smith, E. A., \& Wishnie, M. (2000). Conservation and subsistence in small-scale societies. Annual Review of Anthropology, 29(2000), 493-524. https://doi.org/10.1146/annurev.anthro.29.1.493

Sperber, D. (1985). Anthropology and psychology: Towards an epidemiology of representations. Man, 20(1), 73-89.

Spielmann, K. A. (1986). Interdependence among egalitarian societies. Journal of Anthropological Archaeology, 5, 279-312.

Stanley, S. M. (1992). An ecological theory for the origin of Homo. Paleobiology, 18(3), 237-257. https://doi.org/10.1017/S0094837300010836

Sterelny, K., \& Griffiths, P. E. (1999). Sex and Death: An Introduction to the Philosophy of Biology. University of Chicago Press.

Stinson, S., Bogin, B., O’Rourke, D. H., \& Huss-Ashmore, R. (2012). Human biology: An evolutionary and biocultural perspective. In S. Stinson, B. Bogin, \& D. H. O’Rourke (Eds.), Human Biology: An Evolutionary and Biocultural Perspective (pp. 3-22). John Wiley \& Sons.

Sutton, M. Q., \& Anderson, E. N. (2014). Introduction to Cultural Ecology. AltaMira Press.

Thornton, T. F., \& Manasfi, N. (2011). Adaptation-Genuine and Spurious: Demystifying Adaptation Processes in Relation to Climate Change. Environment and Society, 1(1), 132155. https://doi.org/10.3167/ares.2010.010107

United Nations Environment Program. (2019). Maladaptation to climate change: Avoiding pitfalls on the evolvability pathway. In Frontiers 2018/19 Emerging Issues of Environmental Concern (pp. 66-76). United Nations Environment Program. https://wedocs.unep.org/bitstream/handle/20.500.11822/27545/Frontiers1819_ch5.pdf

Vayda, A. P., \& McCay, B. J. (1975). New directions in ecology and ecological anthropology. Annual Review of Anthropology, 4(1), 293-306. https://doi.org/10.1146/annurev.an.04.100175.001453

Waddell, E. (1975). How the Enga cope with frost: Responses to climatic perturbations in the Central Highlands of New Guinea. Human Ecology, 3(4), 249-273. 
Waring, T. M., Kline, M. A., Brooks, J. S., Goff, S. H., Gowdy, J., Janssen, M. A., Smaldino, P. E., \& Jacquet, J. (2015). A multilevel evolutionary framework for sustainability analysis. Ecology and Society, 20(2). https://doi.org/10.5751/ES-07634-200234

Wiessner, P. (1982). Risk, reciprocity and social influences on !Kung San economics. In Politics and History in Band Societies (pp. 61-84). Cambridge University Press.

Winterhalder, B. (1980). Environmental analysis in human evolution and adaptation research. Human Ecology, 8(2), 135-170. https://doi.org/10.1007/BF01531439

Xu, C., Kohler, T. A., Lenton, T. M., Svenning, J.-C., \& Scheffer, M. (2020). Future of the human climate niche. Proceeding of the National Academies of Sciences. https://doi.org/10.1073/pnas.1910114117

Zalasiewicz, J. A. N., Williams, M., Steffen, W., \& Crutzen, P. (2010). The new world of the anthropocene. Environmental Science and Technology, 44(7), 2228-2231. https://doi.org/10.1021/es903118j 